\title{
Influence of Accompanied Encounters on Patient- Centeredness with Older Patients
}

\author{
Cleveland G. Shields, PhD, Ronald M. Epstein, MD, Kevin Fiscella, MD, MPH, \\ Peter Franks, MD, Robert McCann, MD, Kevin McCormick, MD, PhD, and \\ Julie B. Mallinger, $B A$
}

Objectives: To conduct a pilot study to examine physician patient interaction when elderly patients are accompanied during a medical visit.

Metbods: This was a study in which 30 patients were randomly assigned to be accompanied (13) or unaccompanied (17) during a regular medical visit to their physician. Visits were tape recorded, transcribed, and coded with the Measure of Patient-Centered Communication (MPCC) and with the Rochester Participatory Decision-Making Scale (RPAD).

Results: We found no differences between the number of words spoken in accompanied versus unaccompanied visits, comparing patients alone with patients and companions combined. Physicians spoke longer without interruption in accompanied encounters (39.9 vs 78.6 words per speech turn). There were no differences in the level of MPCC or in the level of participatory decision making between the 2 types of visits. In accompanied visits, patients introduced most of the concerns and physicians discussed concerns with patients more than with companions.

Conclusions: Previously reported differences in accompanied versus unaccompanied visits may reflect patients' preferences for being accompanied, the role they wish their companion to play, and the patients' health status. Being accompanied by a family member or friend does not result in less attention being paid to patients' concerns. (J Am Board Fam Pract 2005;18:344-54.)

Older patients are frequently accompanied to medical visits ${ }^{1-4}$ but it is unknown if the presence of a companion improves or interferes with clinical care. Estimates vary as to the frequency of family members in medical visits but studies have found that companions attend between $20 \%$ and $37 \%$ of older adults' medical visits. ${ }^{3-6}$ Researchers have documented both negative $e^{5,7}$ and positive ${ }^{6,8}$ effects associated with accompanied visits. For example, Green and associates ${ }^{7}$ stated that individual patients get less attention from physicians when fam-

Submitted, revised, 24 May 2005.

From the University of Rochester Medical Center, Department of Family Medicine, Rochester Center to Improve Communication in Health Care (CGS, RME, KF), University of Rochester School of Medicine, Department of Medicine, Highland Hospital (RM, KM), Hematology/Oncology (JBM), Rochester, NY; and University of California, Department of Family and Community Medicine, Center for Health Services Research in Primary Care, Sacramento, CA (PF).

Funding: This research was supported by National Institute on Aging Grant R03 AG18650 (to CGS).

Conflict of interest: none declared.

Corresponding author: Cleveland G. Shields, $\mathrm{PhD}$, University of Rochester Medical Center, Department of Family Medicine, Rochester Center to Improve Communication in Health Care, 1381 South Avenue, Rochester, NY 146202830 (e-mail: Cleveland_Shields@urmc.Rochester.edu). ily members are present in the session. Adelman et $\mathrm{al}^{5}$ suggested that family members may have different agendas than the patient or they may not always have the best interests of the patient at heart, which may disrupt the physician-patient relationship. Levine et $\mathrm{al}^{8}$ have argued that many clinicians are so focused on individual patients that they do not know how to interact with family members. On the other hand, Schilling et $\mathrm{al}^{6}$ found that physicians and patients both rated companions' effect on accompanied visits as positive. Many patients want to bring family members into the session with them. ${ }^{4}$ Some physicians are uncomfortable with this because they think it may distract from the patients' needs. ${ }^{5,9}$ These observational studies, however, are potentially limited by selection bias. Patients who are regularly accompanied to their medical visits may systematically differ from patients who are not, in ways that affect communication.

To address this limitation, we conducted a pilot study to examine the role of accompanied visits using a randomized study design. We measured communication in the encounters within the framework of patient-centered communication (PCC). PCC refers to communication that has 3 
goals for health care providers: (1) seeking to understand patients' perspectives of their problems such that patients' reasons for visit, feelings, ideas, functioning, and expectations are on equal footing with the diagnostic imperative ${ }^{9-12}$; (2) understanding patients' psychosocial context, which means that health care providers need to explore patients' family, work, and social situation; and (3) encouraging participatory decision making in which health care providers seek to explain the diagnosis and treatment plans in understandable language and encourage patients to ask questions and engage in dialogue about the diagnosis and treatment plan. PCC is associated with higher levels of satisfaction, ${ }^{13-16}$ and improved biomedical and functional outcomes, ${ }^{17-20}$ and may also be associated with higher rates of detection of mental and emotional distress. $^{21-30}$

The aim of this study was to examine the influence of accompanied visits on physician-patient communication. Based on the prior observational literature, we were most interested in examining whether accompaniment resulted in poorer communication between physicians and patients. Using a randomized study design, we examined whether patients in accompanied versus unaccompanied visits received lower levels of attention and focus on their concerns from their physicians.

\section{Methods \\ Participants}

Patients were eligible for the study if they were at least 65 years old, were not cognitively impaired, had a companion who could accompany them to their next visit, and were willing to be randomized. Patients were recruited through a large residencybased family medicine practice and a small hospital-based geriatric practice. At each site, consecutive patients were informed by their physicians about the study and asked whether they would be willing to talk with a research assistant (RA) about it. If they were, they met with the RA who described the study to them and ascertained whether the patient had a spouse, family member, or friend that they would be willing to ask to accompany them to their next visit.

\section{Informed Consent}

The study was approved by the University of Rochester Research Subjects Review Board (approval no.
8429). The RA explained the study and carefully reviewed the informed consent form with the patient and any family members present. Once consent was received, the RA conducted the MiniMental Status Examination ${ }^{31}$ to screen for signs of cognitive problems. After the screening, the RA arranged to interview the patient either on the telephone or in their home to complete a pre-visit questionnaire. The day before the visit, patients were telephoned to remind them of their appointment, that we would be audio taping the visit, and to bring their companion to the visit, if that was their assigned condition.

\section{Interventions}

Patients were assigned to come to the next visit either with or without a companion. No other instructions were given. Companions were not assigned a specific role during the session. Physicians were not asked to conduct the sessions in any particular manner.

\section{Randomization}

The project coordinator wrote "accompanied" or "unaccompanied" on $3 \times 5$ cards and placed them in sealed envelopes. Envelopes were then randomly selected one at a time from a box and given case numbers from 1 to 60 . Once a patient was enrolled in the study and assessed, the research assistant would open the appropriate envelope and inform the patient of the assignment to come to their next visit accompanied or unaccompanied.

\section{Blinding}

It was impossible to blind patients or physicians to their assignments after randomization. In addition, it was not possible to blind the coders as to whether they were coding a companion case or not; however, they were not told the hypotheses of the study.

\section{Objectives}

The primary purpose of this pilot study was to examine whether there were differences in the level of patient-centered communication between accompanied and unaccompanied medical encounters. Because many patients desire to be accompanied and some researchers are concerned about negative consequences of accompanied encounters on communication, we were most interested in 
whether accompanied encounters would result in lower levels of patient-centeredness.

\section{Outcomes: Communication Measures}

First, we examined the number of speech turns, words per speech, and total words of each participant. Second, we measured PCC using the Measure of Patient Centered Communication (MPCC). ${ }^{24}$ Third, we measured more closely one aspect of PCC, whether physicians encouraged participatory decision making, using the Rochester Participatory Decision Making Scale (RPAD). ${ }^{32}$

\section{Number of Speech Turns, Number of Speeches, Words Per speech, and Words Per Visit}

The content of each medical visit was transcribed. For each visit, using a computer algorithm in SAS, we calculated the total number of times each person spoke (number of speech turns). We also calculated words per speech turn, and total number of words spoken for physicians, companions, and patients.

\section{MPCC}

The audio recordings were coded using the MPCC. ${ }^{24}$ The MPCC was based on a scale developed in 1986 then revised in 1995 and 2001. ${ }^{10,24}$ Current and earlier versions of the MPCC demonstrate interrater reliabilities of 0.80 to 0.83 and show a correlation of 0.85 with global ratings of the physician-patient relationship. ${ }^{33}$

The MPCC measures 3 aspects of PCC. Component 1 ("exploring both the disease and the illness experience") measures the degree to which the physician explores the patient's symptoms, ideas, expectations, feelings, and the effect of the symptoms on functioning. Component 2 ("understanding the whole person") measures the degree to which the physician explores the patient's family, social network, job, and interests as they relate to the presenting medical concerns. Component 3 ("finding common ground") measures the degree to which the physician explains the findings and involves the patient in generating a diagnosis and treatment plan. Examples of exchanges from this study relevant to each component are provided in Figure 1.

Three coders were trained to code the audiotapes using the MPCC system. One investigator (CGS) was the "trainer" and 2 RAs coded the tran- scripts and brought questions to the trainer. The interrater reliability between the 2 RAs was 0.79 for the overall MPCC scale. Interrater reliabilities for the 3 components were 0.85 for component $1,0.91$ for component 2 , and 0.65 for component 3 . This compares favorably to the 0.73 reliability for the MPCC total score found by the developers of the scale, who do not report reliabilities for individual components. $^{33}$

In our study, we modified the MPCC scale to code patient and companion interactions with the physicians separately. We were thus able to calculate scores based solely on physician-patient communication or physician-companion communication. Higher scores on the MPCC components indicate that physicians spent more time and effort in discussing or following up on specific issues raised by patients or companions. We also counted the number of issues raised by patients and by companions in each of the 3 components of the MPCC.

$R P A D$

The RPAD is an observational scale that measures physician behaviors that encourage patients' participation in decision making. RPAD is associated with patient satisfaction and trust in their physician. ${ }^{32}$ It is a 9 -item scale in which coders rate, on a 0 to 2 scale, how well a physician completed a certain behavior. For example, clarification of agreement is coded as follows: $0=$ no evidence, $1=$ patient expressed passive assent, and $2=$ physician actively asks for patient agreement and tries to obtain a commitment from the patient to the treatment plan. The intraclass correlation for coding the RPAD was 0.75 .

\section{Sample Size}

Minimum necessary sample size was calculated based on previously published psychometric properties of the MPCC component 1 . We decided a priori that a difference of 0.1 points on the MPCC component 1 scale would be clinically meaningful. Analysis demonstrated that at a 2 -sided $\alpha$ of 0.05 and power of $80 \%, 34$ patients were necessary to show a statistically significant difference.

\section{Statistical Analysis}

Data were analyzed using SAS, version 8.02 (SAS Institute, Inc., Cary, NC). We used multilevel 
Flow of Participants through each Phase of the Randomized Trial

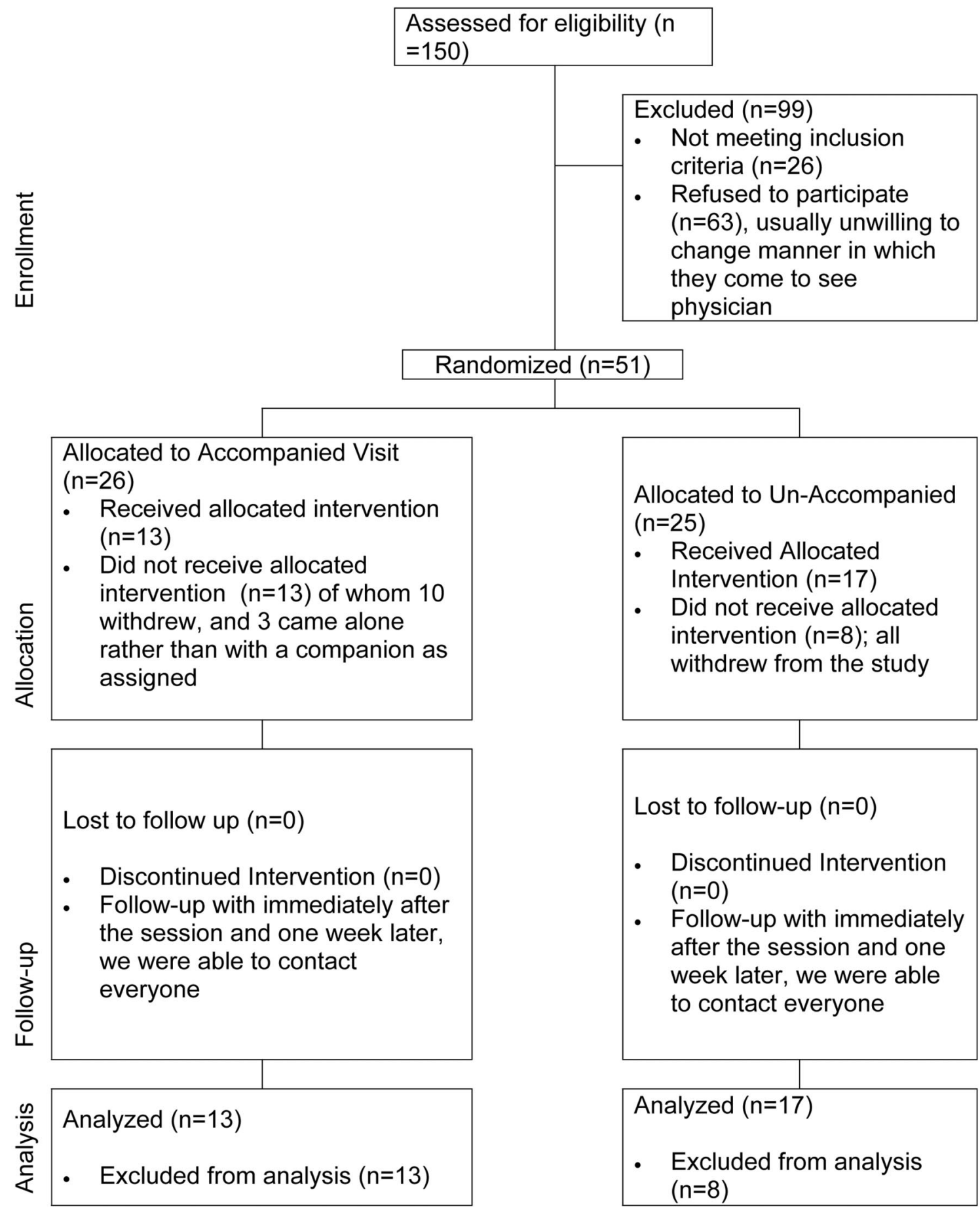

Figure 1. Flow of Participants through Each Phase of the Randomized Trial.

modeling techniques to control for patient nesting within physicians. Although our hypothesis was directional, all tests were conducted conservatively as 2-sided with $\alpha=0.05$.
Results

\section{Participant Flow}

Figure 2 shows the flow of participants through each phase of the trial. One hundred fifty patients 
Component 1 - Exploring Both the Disease and the lllness Experience

Patient: The thing that bothers me most is the tightness in my chest, and l've been

coughing like crazy.

Doctor: When did the cough start?

Patient: Five weeks ago.

Companion: It wakes her up at night.

Doctor: Is that separate from the tightness or the same thing?

Patient: Well, I feel tight all the time.

Doctor: Do you feel as though you can't get a full breath?

Patient: I don't think so. And my voice doesn't sound right to me.

Companion: It sounds more froggy.

Doctor: Yes, you do sound hoarse.

Component 2 - Understanding the Whole Person

Doctor: So you're moving?

Patient: Well, it's so noisy over there and l've been there so long. I've been there since '68.

Doctor: Wow, that's a long time. So where are you moving to?

Patient: Closer to you all over here.

Doctor: Might make it easier.

Patient: Yeah, I hope so. At least l'll be by myself, you know. Like now, my daughter is there, and it's too many people to a house.

Doctor: That sounds like it probably is a good idea then. When are you moving?

Patient: He said I could pick up the key on the first.

Component 3 - Finding Common Ground

Doctor: How would you feel about trying some medication for your depression?

Patient: But wouldn't it make me feel strange?

Doctor: Not usually with this medication. Some medications make people feel spacey or sleepy.

Patient: I don't want to feel like that.

Doctor: I don't think this would make you feel like that at all. And if we did it, I'd start you at a very low dose.

Patient: All right. Now how would I take it?

Doctor: You can take it any time.

Patient: On an empty stomach?

Doctor: On an empty stomach or a full stomach, morning or afternoon.

Patient: Ok.

Doctor: Do you want to give this a try and just see how it works?

Patient: I'll give it a try.

Figure 2. Examples of Exchanges Relevant to Each Component of the MPCC.

were assessed for eligibility. Of the 99 patients who were excluded, 26 did not have an available companion, and 63 said that they did not want to change their usual manner of seeing the physician. Fifty-one patients were randomized to 2 conditions: accompanied (26) versus unaccompanied (25) visits. Only 13 of the 26 assigned to the accompanied condition completed that condition. Ten withdrew from the study and 3 came alone to the visit rather than with a companion. Only 17 patients assigned to the unaccompanied condition completed that condition. Eight patients in the unaccompanied group withdrew from the study and 7 from the accompanied group withdrew. Most withdrawals occurred because patients changed their minds about being audio taped, were unable to get a companion to accompany them, felt the study was "too much," or had new serious medical problems arise. No patients who completed their condition were lost to follow up, because we obtained follow-up measures immediately after the visit before the patient had a chance to return home. Thus, we analyzed a total of 30 patient visits, of which 13 were accompanied and 17 were unaccompanied. 
The companions consisted of 5 daughters (with 3 mothers and 2 fathers), 2 sons (with their fathers), 1 female friend of a male patient, and 5 spouses (1 husband and 4 wives).

\section{Recruitment}

Patients were recruited from September 2000 through February 2003.

\section{Baseline Data}

There were no differences on any of the baseline measures between patients in the 2 groups (Table 1).

\section{Outcomes and Estimations}

Speech Turns, Mean and Maximum Words per Turn, and Total Words

Table 2 shows the average total number of words spoken by each participant, number of speech turns, maximum length of speech, and average length of speech for accompanied and unaccompanied visits. In accompanied encounters, physicians spoke, on average, 38.1 more words than in unaccompanied encounters, although they spoke fewer times (143.4 speech turns vs 158.5 speech turns). Relatedly, physicians made longer speeches in accompanied visits (average speech $=11.3$ words)

Table 1. Patient Demographics*

\begin{tabular}{lrrrrr}
\hline & \multicolumn{2}{c}{$\begin{array}{c}\text { Unaccompanied } \\
(\mathrm{n}=13)\end{array}$} & & \multicolumn{2}{c}{$\begin{array}{c}\text { Accompanied } \\
(\mathrm{n}=17)\end{array}$} \\
\cline { 2 - 3 } Variable & Mean & $(\mathrm{SD})$ & & Mean & $(\mathrm{SD})$ \\
\hline Age & 66.1 & $(15.5)$ & 68.5 & $(11.7)$ \\
Years of education & 13.6 & $(3.4)$ & 14.1 & $(2.2)$ \\
Number of children living & 3.0 & $(1.9)$ & & 2.4 & $(1.1)$ \\
Mini Mental Status & 27.6 & $(1.9)$ & 28.0 & $(1.9)$ \\
Household income† & $\$ 35.7$ & $(\$ 34.2)$ & $\$ 35.7$ & $(\$ 29.4)$ \\
General health (SF-36) & 61.3 & $(8.2)$ & 62.5 & $(9.2)$ \\
Geriatric depression scale & 8.7 & $(6.0)$ & 9.1 & $(8.6)$ \\
\hline & $\mathrm{n}$ & $(\%)$ & $\mathrm{n}$ & $(\%)$ \\
\hline Female & 12 & $(75)$ & 8 & $(66)$ \\
Living with spouse & 8 & $(53)$ & 6 & $(54)$ \\
Driving a car & 7 & $(44)$ & 7 & $(47)$ \\
Raceł & & & & \\
Caucasian & 12 & $(75)$ & 12 & $(92)$ \\
African American & 2 & $(13)$ & 0 & $(0)$ \\
Other & 2 & $(13)$ & 1 & $(8)$ \\
\hline
\end{tabular}

* There were no significant demographic differences between groups ( $t$ tests not shown).

$\dagger$ Income is in thousands, $\$ 35.7=\$ 35,700$.

$\ddagger$ Due to rounding, percentage may not add up to $100 \%$. than in unaccompanied visits (average speech $=7.8$ words; $P=.02)$.

By contrast, patients spoke an average of 270.3 fewer words in accompanied encounters and had an average of 17.2 fewer speech turns, although neither of these differences was statistically significant. Patients' speeches in accompanied visits (average $=$ 9.6 words) were only slightly longer than in unaccompanied visits (average $=8.5$ words). In accompanied visits, companions spoke relatively few words (average $=313.6$ words), had fewer speech turns (average $=34.8$ turns), and had shorter speeches (average $=7.8$ words) than patients or physicians.

\section{Number of Issues or Concerns Raised}

Table 3 shows the number of issues and concerns raised in accompanied and unaccompanied visits. In accompanied visits, patients raised more issues than companions. For example, patients raised an average of 6.2 issues related to exploring the disease or illness (MPCC component 1), whereas companions raised an average of 2.7 issues on this topic. Both patients and companions raised an average of less than one issue related to the patient's context (MPCC component 2). Patients and companions also raised fewer issues about the diagnosis and treatment plan (MPCC component 3), with patients raising an average of 3.2 issues and companions raising an average of 1.5 issues.

Patients raised more issues in unaccompanied visits as opposed to accompanied visits, although the differences were small. For example, patients who were unaccompanied raised an average of 6.6 issues related to exploring the disease or illness, whereas patients who were accompanied raised an average of 6.2 issues on this topic. Mixed-model tests showed that there were no statistically significant differences between accompanied and unaccompanied visits on the number of issues that patients raised. Furthermore, the total number of issues raised by companions and patients in the accompanied visits was not significantly different from the number of issues raised by patients alone in the unaccompanied visits (data not shown).

PCC

Table 4 shows the results of mixed model tests examining differences between PCC in physicians' responses to the patients in accompanied and un- 


\begin{tabular}{|c|c|c|c|c|c|c|c|}
\hline \multirow[b]{2}{*}{ Variable } & \multicolumn{2}{|c|}{$\begin{array}{l}\text { Unaccompanied } \\
(\mathrm{n}=17)\end{array}$} & \multicolumn{2}{|c|}{$\begin{array}{c}\text { Accompanied } \\
(\mathrm{n}=13)\end{array}$} & \multicolumn{2}{|c|}{ Mean Difference } & \multirow[b]{2}{*}{$P$ Value } \\
\hline & Mean & $(\mathrm{SD})$ & Mean & $(\mathrm{SD})$ & Mean & (95\% C.I.) & \\
\hline \multicolumn{8}{|c|}{ Length (number of words) } \\
\hline Companion & 313.6 & (256.6) & & & & & \\
\hline Physician & 1890.1 & $(853.4)$ & 1940.1 & $(627.7)$ & -38.1 & $(-594.0,517.8)$ & .85 \\
\hline Patient & 1770.2 & $(988.9)$ & 1478.0 & $(986.7)$ & 270.3 & $(-441.2,981.7)$ & .44 \\
\hline \multicolumn{8}{|c|}{ Number of speech turns } \\
\hline Companion & & & 34.8 & $(27.9)$ & & & \\
\hline Physician & 158.5 & $(55.2)$ & 143.4 & $(55.9)$ & 15.9 & $(-25.18,56.8)$ & .45 \\
\hline Patient & 158.1 & $(55.0)$ & 141.7 & $(59.1)$ & 17.2 & $(-24.9,59.2)$ & .43 \\
\hline \multicolumn{8}{|c|}{ Maximum length of speeches (number of words) } \\
\hline Companion & & & 31.5 & $(25.4)$ & & & \\
\hline Physician & 39.9 & $(31.5)$ & 78.6 & $(53.1)$ & -38.6 & $(-70.1,-7.2)$ & $.03^{*}$ \\
\hline Patient & 60.8 & $(74.7)$ & 100.1 & $(75.2)$ & -39.3 & $(-94.6,16.0)$ & .57 \\
\hline \multicolumn{8}{|c|}{ Mean length of speeches (number of words) } \\
\hline Companion & & & 7.8 & (3.4) & & & \\
\hline Physician & 7.8 & (3.4) & 11.3 & (4.4) & -3.8 & $(-6.6,-0.9)$ & $.02^{*}$ \\
\hline Patient & 8.5 & $(5.1)$ & 9.6 & $(5.0)$ & -1.1 & $(-4.8,2.7)$ & .57 \\
\hline
\end{tabular}

accompanied encounters. No trend was demonstrated for level of patient-centeredness between the 2 types of visits. That is, physicians had slightly higher PCC scores for component 1 (exploring the disease and illness) in unaccompanied visits, but slightly lower PCC scores for component 3 (diagnosis and treatment) in these same visits. These differences were not statistically significant. $\mathrm{Pa}-$ tients who were in the accompanied group reported being slightly more satisfied (mean score $=34.5$ ) than patients in the unaccompanied group (mean score $=32.5$ ), but again, this difference was not statistically significant.

We also examined differences in physicians' levels of patient-centeredness with patients versus with companions within only the accompanied visits. Table 5 shows the results of the paired $t$ tests. On all measures of PCC and RPAD (participatory decision making), physicians demonstrated higher levels of patient-centeredness with patients compared with with companions. For example, physicians were more responsive to issues regarding exploring the disease and illness (MPCC component 1) when these issues were raised by the patient (MPCC score $=0.59)$ compared with the companion (MPCC score $=0.41 ; P=.03$ ). Likewise, physicians received higher MPCC scores related to understanding the whole person (MPCC component 2) and diagnosis and treatment (MPCC component 3) when related issues were raised by the patient. Physicians were also more likely to encourage collaboration in treatment decision making with patients $(\mathrm{RPAD}=6.06)$ than with companions $(\mathrm{RPAD}=4.70 ; P<.0001)$.

\section{Adverse Events}

There were no adverse events resulting from patients' and companions' participation in the study.

Table 3. Number of Issues Raised by Patients and Companions during the Visit, by MPCC* Component

\begin{tabular}{|c|c|c|c|c|c|c|c|}
\hline \multirow[b]{2}{*}{ Variable } & \multicolumn{2}{|c|}{$\begin{array}{l}\text { Unaccompanied } \\
\quad(\mathrm{n}=16)\end{array}$} & \multicolumn{2}{|c|}{$\begin{array}{l}\text { Accompanied } \\
(\mathrm{n}=15)\end{array}$} & \multicolumn{2}{|c|}{ Mean Difference } & \multirow[b]{2}{*}{$P$ Value } \\
\hline & Mean & (SD) & Mean & $(\mathrm{SD})$ & Mean & (95\% C.I.) & \\
\hline \multicolumn{8}{|l|}{ Companions } \\
\hline Component 1 exploring disease and illness & & & 2.7 & $(1.6)$ & & & \\
\hline Component 2 whole person & & & 0.2 & $\left(0.4^{\dagger}\right)$ & & & \\
\hline Component 3 diagnosis and treatment & & & 1.5 & $\left(1.0^{\dagger}\right)$ & & & \\
\hline \multicolumn{8}{|l|}{ Patients } \\
\hline Component 1 exploring disease and illness & 6.6 & $(2.8)$ & 6.2 & $(2.9)$ & 0.3 & $(-1.8,2.5)$ & .75 \\
\hline Component 2 whole person & 0.9 & $(1.0)$ & 0.5 & $(0.8)$ & 0.4 & $(-0.3,1.1)$ & .26 \\
\hline Component 3 diagnosis and treatment & 3.9 & (1.3) & 3.2 & $(1.5)$ & 0.7 & $(-0.3,1.8)$ & .16 \\
\hline
\end{tabular}

* MPCC, Measure of Patient-Centered Communication.

$\dagger$ MPCC $1>\operatorname{MPCC} 2(t=5.34, P<.000)$ and MPCC $1>\operatorname{MPCC} 3(t=2.19, P=.055)$. 
Table 4. Patient-Centeredness of Responses to the Patient in Accompanied and Unaccompanied Encounters

\begin{tabular}{|c|c|c|c|c|c|c|c|}
\hline & \multicolumn{2}{|c|}{ Accompanied } & \multicolumn{2}{|c|}{ Unaccompanied } & \multicolumn{2}{|c|}{ Adjusted Mean } & \multirow[b]{2}{*}{$P$ Value } \\
\hline & Mean & $(\mathrm{SD})$ & Mean & $(\mathrm{SD})$ & Difference & (95\% C.I.) & \\
\hline \multicolumn{8}{|l|}{$\mathrm{MPCC}^{*}$} \\
\hline Component 1 exploring disease and illness & 0.59 & $(0.02)$ & 0.60 & $(0.04)$ & -0.01 & $(-0.03,0.02)$ & 0.43 \\
\hline Component 2 whole person & 0.31 & $(0.32)$ & 0.31 & $(0.32)$ & 0.02 & $(-0.22,0.27)$ & 0.83 \\
\hline Component 3 diagnosis and treatment & 0.66 & $(0.13)$ & 0.65 & $(0.15)$ & -0.01 & $(-0.10,0.11)$ & 0.91 \\
\hline RPAD total & 6.06 & $(1.59)$ & 5.92 & $(1.08)$ & 0.15 & $(-0.97,1.27)$ & 0.78 \\
\hline Satisfaction & 34.45 & $(5.22)$ & 32.52 & $(3.72)$ & -1.54 & $(-5.17,2.08)$ & 0.38 \\
\hline
\end{tabular}

* MPCC, Measure of Patient-Centered Communication; RPAD, Rochester Participatory Decision-Making Scale.

\section{Discussion}

Contrary to the expectations of some researchers, ${ }^{2,5}$ we found few systematic differences in physician-patient communication in accompanied compared with unaccompanied visits, and thus no evidence that the presence of a companion diverts physicians' attention from the patients' concerns. There were no differences in the number of words spoken or number of speech turns between accompanied and unaccompanied visits. We found no differences in the number of topics or concerns raised by patients in the 2 groups. We found no differences in PCC scores between accompanied and unaccompanied visits. Physicians followed up on patient medical concerns, patient social and contextual issues, discussed diagnosis and treatment recommendations at the same depth in both accompanied and unaccompanied visits. We also found no differences in the level of participatory decision-making between the 2 groups. The only difference we found was in speech length, the impact of which is unclear.

Physicians gave more attention to the concerns and topics raised by patients than by companions in the accompanied visits, suggesting that attention to patients was not compromised by the presence of a companion. All measures of PCC showed that physicians followed up and asked more questions of the patients than of the companions. In other words, the presence of the companion did not seem to divert physician's attention away from the patients and physicians primarily discussed these issues with the patients and not with the companions. Companions did bring up issues, but they then tended to be pursued with the patient. Thus, companions actually seemed to facilitate patient-physician discussions by bringing up new issues, and then permitting the physician and patient to explore them further.

We found no other reports of clinical trials of accompanied visits in the literature, making this the first randomized study to examine the effect of having a third person in a medical visit. Our results compare most directly to Greene et $\mathrm{al}^{2}$ who conducted a nonrandomized study of 30 elderly visits in which 15 were accompanied and 15 were not. Patients who had been accompanied to their visits were matched with unaccompanied patients on gender and race. Using their coding system, ${ }^{2}$ they found that patients in accompanied visits raised fewer issues for discussion with the physician than did patients who were unaccompanied. The combined number of topics raised by patients and companions did not differ from the number of topics in unaccompanied visits. As in our study (using the MPCC as a measure), there was no difference in physician responsiveness between the 2 groups. Also consistent with our findings was their obser-

Table 5. Physician Interaction in Accompanied Visits Patient versus Companions

\begin{tabular}{|c|c|c|c|c|c|c|c|}
\hline & \multicolumn{2}{|c|}{ Patient } & \multicolumn{2}{|c|}{ Companion } & \multicolumn{2}{|c|}{ Difference } & \multirow[b]{2}{*}{$P$ Value } \\
\hline & Mean & $(\mathrm{SD})$ & Mean & $(\mathrm{SD})$ & Mean & $(95 \% \mathrm{CI})$ & \\
\hline \multicolumn{8}{|l|}{$\mathrm{MPCC}^{*}$} \\
\hline Component 1 exploring disease and illness & 0.59 & $(0.02)$ & 0.41 & $(0.25)$ & -0.21 & $(-0.37,-0.05)$ & .03 \\
\hline Component 2 whole person & 0.31 & $(0.32)$ & 0.10 & $(0.23)$ & -0.15 & $(-0.30,0.01)$ & .06 \\
\hline Component 3 diagnosis and treatment & 0.66 & $(0.13)$ & 0.43 & $(0.21)$ & -0.28 & $(-0.44,-0.13)$ & $<.0001$ \\
\hline RPAD total & 6.06 & $(1.59)$ & 4.70 & $(0.67)$ & -1.30 & $(-1.98,-0.62)$ & $<.0001$ \\
\hline
\end{tabular}

* MPCC, Measure of Patient-Centered Communication; RPAD, Rochester Participatory Decision Making Scale. 
vation that companions mostly raised medical issues, not psychosocial or treatment issues. In contrast to our study, however, they found less joint decision-making in accompanied visits.

Part of the discrepancy in findings may be explained by differences in health status between the 2 groups in the study by Greene et al. ${ }^{2}$ Poorer health in accompanied patients may have affected patient-physician interactions, such as the number of topics raised by patients and the role of companions. ${ }^{34}$ In addition, we controlled for patient preferences for being accompanied and patient health status by randomly assigning patients to come alone or accompanied to the medical visit.

A statistically significant finding of this study was that physicians in accompanied visits made longer speeches. One possible explanation may be that physicians feel a stronger need to hold the floor and control the session because they experience the accompanied visit as more complex and more in need of structure. They may also speak longer because they may be addressing themselves to both patient and companion and need assure that both have been included in questioning and explanations. However, we found no differences in the overall number of words spoken (a proxy for the length of the visits) between the 2 conditions.

The primary limitation of this study is that findings from a randomized study design may not translate to the "real world" setting. That is, patients may choose to attend their medical visits either accompanied or unaccompanied depending on their unique needs and wishes. It would be inadvisable to draw conclusions from this study as to whether patients "should" or "should not" bring a companion to their medical visits. Nonetheless, a randomized study offers some advantage over a naturalistic study in that it allows us to distinguish between the effect of accompaniment and the effect of patient characteristics that are likely to be highly correlated with preference for accompaniment. By randomizing patients to an accompaniment group, we theoretically remove the effect of patient behavior patterns and interaction styles, and isolate the effect of accompaniment on physician-patient communication. This may allow us to better understand the complex doctor-patient relationship. Further, a randomized study is an effective way to measure physician response to family members in the medical visit, as randomization again should eliminate the bias caused by patient preferences and behaviors.

The high refusal rate for this study may limit the generalizability of our findings. Over one third (42\%) of patients approached for this study declined because they did not want to change their usual pattern of seeing a physician. That is, many patients who generally saw a physician alone were uncomfortable with having another person attend the consultation; likewise, many patients who generally brought a companion to their visits were not willing to attend a medical visit alone. This may limit the generalizability of our findings if patients who refused the study or did not comply with randomization were systematically different from the patients who enrolled and completed the study. The high refusal rate for this study does, however, provide an interesting insight into patient preferences for medical care. We found that elderly patients are likely to be resistant to changing their usual pattern of accompaniment, which suggests that it is important for physicians to accommodate patients' preferences for including or excluding family members from the medical consultation.

Related to this issue is the fact that our final sample size was relatively small, limiting our ability to demonstrate statistical significance even in instances where a trend may have been suggested. For example, although we found that patients in accompanied visits spoke an average of 270 fewer words than patients in unaccompanied visits, this difference was not statistically significant. Although our study was underpowered to show that this finding was unlikely to occur by chance alone, it is consistent with another finding that the total number of words spoken in accompanied and unaccompanied visits was very similar. These results, together, suggest that physicians may not spend more time with patients who are accompanied, and thus, time that the physician spends interacting with the companion may detract from time spent interacting with the patient. The clinical significance of this result must be considered separately from the issue of statistical significance. We cannot say conclusively that the number of words spoken by a patient is related to the quality of the medical visit. Our results do suggest, though, that physicians are equally patient-centered in accompanied and unaccompanied medical visits. Additional research is needed in larger samples to more precisely estimate 
any differences that may exist between accompanied and unaccompanied medical encounters.

Another potential limitation of this study is that patients and physicians were not blinded to their assignment, and physicians in the active group may have altered their practice. Some of the outcome assessments, such as the MPCC, could not be blinded, thus potentially biasing the assessment of outcomes. Finally, the measures of PCC may not have been sensitive enough to detect true differences between the 2 groups.

Despite these limitations, our study, the first to randomize patients to accompanied and unaccompanied visits, suggests that companions accompanying patients to encounters do not adversely affect the physician patient communication in the visit. These findings should be replicated in a larger study that will have statistical power to detect more subtle differences. If our findings are confirmed, naturalistic (noninterventional) studies may help to further explain the effects of patients' preferences and behaviors versus presence of a companion on physician-patient communication. In addition, further research is necessary to determine whether patient outcomes are ultimately affected by the presence or absence of a companion in medical visits.

\section{References}

1. Beisecker AE. The influence of a companion on the doctor-elderly patient interaction. Health Commun 1989;1:55-70.

2. Greene MG, Adelman R, Charon R, Hoffman S. Ageism in the medical encounter: an exploratory study of the doctor-elderly patient relationship. Lang Commun 1986;6:113-24.

3. Glasser ML, Prohaska T, Roska J. The role of the family in medical care-seeking decisions of older adults. Fam Community Health 1992;15:59-70.

4. Botelho RJ, Lue BH, Fiscella K. Family involvement in routine health care: a survey of patients' behaviors and preferences. J Fam Pract 1996;42:572-6.

5. Adelman RD, Greene MG, Charon R. The physician-elderly patient-companion triad in the medical encounter: the development of a conceptual framework and research agenda. Gerontologist 1987;27: 729-34.

6. Schilling LM, Scatena L, Steiner JF, et al. The third person in the room: frequency, role, and influence of companions during primary care medical encounters. J Fam Pract 2002;51:685-90.

7. Greene MG, Majerovitz SD, Adelman RD, Rizzo C. The effects of the presence of a third person on the physician-older patient medical interview. J Am Geriatr Soc 1994;42:413-9.

8. Levine C, Zuckerman C. The trouble with families: toward an ethic of accommodation. Ann Intern Med 1999;130:148-52.

9. Levenstein JH, McCracken EC, McWhinney IR, Stewart MA, Brown JB. The patient-centred clinical method. 1. A model for the doctor-patient interaction in family medicine. Fam Pract 1986;3:24-30.

10. Brown J, Stewart M, McCracken E, McWhinney IR, Levenstein J. The patient-centred clinical method. 2. Definition and application. Fam Pract 1986;3:75-9.

11. Mead N, Bower P. Patient-centredness: a conceptual framework and review of the empirical literature. Soc Sci Med 2000;51:1087-110.

12. Stewart M, Brown JB, Weston WW, McWhinney IR, McWilliam CL, Freeman TR. Patient-centered medicine: transforming the clinical method. Thousand Oaks (CA): Sage Publications, 1995.

13. Cecil DW, Killeen I. Control, compliance, and satisfaction in the family practice encounter. Fam Med 1997;29:653-7.

14. Little P, Everitt H, Williamson I, et al. Observational study of effect of patient centredness and positive approach on outcomes of general practice consultations. BMJ 2001;323:908-11.

15. Rao JK, Weinberger M, Kroenke K. Visit-specific expectations and patient-centered outcomes: a literature review. Arch Fam Med 2000;9:1148-55.

16. Woodcock AJ, Kinmonth AL, Campbell MJ, Griffin SJ, Spiegal NM. Diabetes care from diagnosis: effects of training in patient-centred care on beliefs, attitudes and behaviour of primary care professionals. Patient Educ Couns 1999;37:65-79.

17. Bass MJ, Buck C, Turner L, Dickie G, Pratt G, Robinson HC. The physician's actions and the outcome of illness in family practice. J Fam Pract 1986; 23:43-7.

18. Henbest RJ, Stewart M. Patient-centredness in the consultation. 2: Does it really make a difference? Fam Pract 1990;7:28-33.

19. Starfield B, Steinwachs D, Morris I, Bause G, Siebert S, Westin C. Patient-doctor agreement about problems needing follow-up visit. JAMA 1979;242: 344-6.

20. Starfield B, Wray C, Hess K, Gross R, Birk PS, D'Lugoff BC. The influence of patient-practitioner agreement on outcome of care. Am J Public Health 1981;71:127-31.

21. Kirmayer LJ, Robbins JM, Dworkind M, Yaffe MJ. Somatization and the recognition of depression and anxiety in primary care. Am J Psychiatry 1993;150: $734-41$.

22. Bertakis KD, Roter D, Putnam SM. The relationship of physician medical interview style to patient satisfaction. J Fam Pract 1991;32:175-81.

23. Robbins JM, Kirmayer LJ, Cathebras P, Yaffe MJ, Dworkind M. Physician characteristics and the rec- 
ognition of depression and anxiety in primary care. Med Care 1994;32:795-812.

24. Brown J, Stewart M, Ryan BL, Brown J, Stewart M, Ryan BL. Assessing communication between patients and physicians: the measure of patient-centered communication (MPCC) working paper series. Paper no. 95-2, Second Edition. London, Ontario Canada, Thames Valley Family Practice Research Unit and Centre for Studies in Family Medicine.

25. Carney PA, Eliassen MS, Wolford GL, Owen M, Badger LW, Dietrich AJ. How physician communication influences recognition of depression in primary care. J Fam Pract 1999;48:958-64.

26. Goldberg DP, Jenkins L, Millar T, Faragher EB. The ability of trainee general practitioners to identify psychological distress among their patients. Psychol Med 1993;23:185-93.

27. Roter DL. Patient participation in the patient-provider interaction: the effects of patient question asking on the quality of interaction, satisfaction and compliance. Health Educ Monogr 1977;5:281-315.

28. Roter DL, Hall JA, Katz NR. Relations between physicians' behaviors and analogue patients' satisfac- tion, recall, and impressions. Med Care 1987;25: 437-51.

29. Roter D. Doctors talking with patients/patients talking with doctors: improving communication in medical visits. Westport (CT): Auburn House, 1992.

30. Goldberg DP, Steele JJ, Smith C, Spivey L. Training family doctors to recognise psychiatric illness with increased accuracy. Lancet 1980;2:521-3.

31. Folstein MF, Folstein SE, McHugh PR. "Mini-mental state". A practical method for grading the cognitive state of patients for the clinician. J Psychiatr Res 1975;12:189-98.

32. Shields CG, Franks P, Fiscella K, Meldrum S, Epstein RM. Rochester Participatory Decision-Making Scale (RPAD): reliability and validity. Ann Fam Med In press.

33. Stewart M, Brown JB, Donner A, McWhinney IR, et al. The impact of patient-centered care on outcomes. J Fam Pract 2000;49:796-804.

34. Hall JA, Milburn MA, Epstein AM. A causal model of health status and satisfaction with medical care. Med Care 1993;31:84-94. 